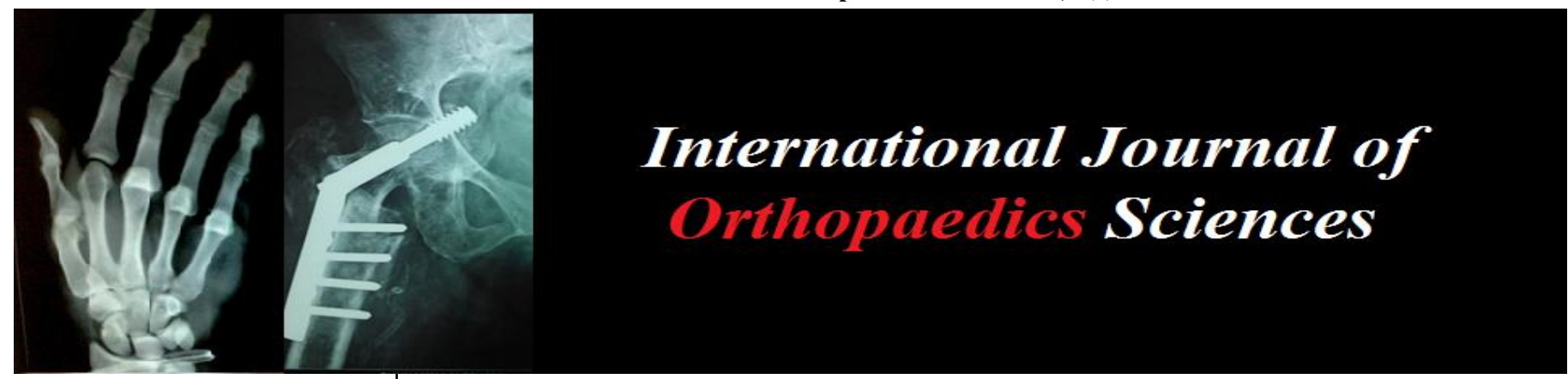

E-ISSN: 2395-1958

P-ISSN: 2706-6630

IJOS 2020; 6(1): 460-463

(C) 2020 IJOS

www.orthopaper.com

Received: 01-11-2019

Accepted: 05-12-2019

\section{B Gavaskar}

Assistant Professor, Department

of Orthopedics, GGH,

Nizamabad, Telangana, India

\section{Rithika Singh}

Siniour Resident, Department of Orthopedics, GGH, Nizamabad,

Telangana, India

\section{Management of diaphyseal long bone fractures in paediatric age group by tens}

\section{B Gavaskar and Rithika Singh}

DOI: https://doi.org/10.22271/ortho.2020.v6.i1i.1907

\section{Abstract}

Background: Diaphyseal fractures in children are among the most common major paediatric injuries treated by orthopaedic surgeons and account for approximately $1.6 \%$ of all fractures seen in this population. Peak incidences occur at $2 \& 17$ years of age in bimodal distribution and boys have 2.6 times greater incidence than girls. The aim of this study is to evaluate the results of operative treatment of paediatric diaphyseal fractures in the age group between 5 to 12 years using titanium elastic nails (TENs).

Material and Methods: This is a Prospective Study based on patients admitted with Diaphyseal Fractures in Long Bones in the age group of 5 years - 12 years in the Department of Orthopaedics, government general hospital attached to government medical college, Nizamabad, study was conducted between March 2016 to March 2017.

Results: In the age group 5years to 8 years there were $14(47 \%)$ and 9 years to 12 years there were 16 patients $(56 \%)$. In our study the fracture was transverse in 15 cases $(50 \%)$, short oblique in 7 cases $(24 \%)$, spiral in 6 cases $(20 \%)$, segmental in $1(3 \%)$ and comminuted in 1 case $(3 \%)$.

Keywords: Diaphyseal fractures, children, TENS, pediatric fractures, long bones, orthopedics

\section{Introduction}

Diaphyseal fractures in children are among the most common major paediatric injuries treated by orthopaedic surgeons and account for approximately $1.6 \%$ of all fractures seen in this population. Peak incidences occur at $2 \& 17$ years of age in bimodal distribution and boys have 2.6 times greater incidence than girls ${ }^{[1]}$.

What constitutes appropriate management of diaphyseal fractures in children is a subject of much debate. Treatment ranges from strictly nonsurgical methods (e.g. closed reduction with casting or traction followed by casting and Pavlik harness for femur fractures) to surgical stabilization (using flexible intramedullary nailing, external fixation, or, sub muscular compression plating and screws).

Nonsurgical management has been the standard of care for most children historically but disadvantages of this treatment include prolonged immobilization and necessitate long hospital stay. Casting with or without traction is still the preferred treatment for diaphyseal fractures in children of preschool age.

The transition from non-operative to operative treatment for Diaphyseal fractures in childhood is not sudden. The growing economic concern, prolonged hospitalization required for traction in younger patients, the family's ability to take care of the child in cast, time spent in bed in conservative treatment and psychological implication of trauma in adolescents have prompted a more aggressive approach in managing these injuries. Operative treatment results in shorter hospitalization and early mobilization, which has psychological, social, educational and economic advantages over conservative treatment.

A variety of therapeutic alternatives mentioned above such as external fixator, compression plating, rigid intramedullary nailing and elastic stable intramedullary nailing are being used for Diaphyseal fractures in children. Several studies have shown that FIN/TENS fixation meets these requirements because it allows rapid mobilization, potentially no risk for osteonecrosis, 
Low risk for physeal injury, and reduced risk for refracture. ESIN meets the requirements of this ideal device (Flynn et al. 2001) ${ }^{[2]}$. Moreover, much of the indexed publication and literature available on TENS is based on studies conducted outside the Indian subcontinent.

Titanium elastic nail (TEN) fixation was originally meant as an ideal treatment method for femoral fractures, but was gradually applied to other long bone fractures in children, as it represents a compromise between conservative and surgical therapeutic approaches with satisfactory results and minimal complications.

The aim of this study is to evaluate the results of operative treatment of paediatric diaphyseal fractures in the age group between 5 to 12 years using titanium elastic nails (TENs).

\section{Material and Methods}

This is a Prospective Study based on patients admitted with Diaphyseal Fractures in Long Bones in the age group of 5 years-12 years in the Department of Orthopaedics, government general hospital attached to government medical college, Nizamabad, study was conducted between March 2016 to March 2017.

\section{Study method}

Case selection criteria: During this period all patients posted for titanium elastic nailing were screened using the inclusion and exclusion criteria. Informed consent was taken from all patients that fit the inclusion criteria and all patients willing to undergo the trial were included. Patients were followed up at regular intervals and outcome variables were assessed and recorded.

The study was done on 30 cases of Diaphyseal fractures. Out of 20 cases 21 were Boys and 9 were Girls.

\section{Inclusion criteria}

1. Children with Diaphyseal fractures of long bones.

2. Age between 5-12 years.

3. Transverse, short oblique and minimally comminuted fractures.

4. Weight below $50 \mathrm{~kg}$.

5. Closed and type I open fractures.

\section{Exclusion criteria}

1. Congenital disorders.

2. Patients who do not give consent.

3. Long oblique, multifragmentary fractures.

4. Medical contraindications to surgery.

5. Children with neuromuscular disease (cerebral palsy).

6. Open grade II and III.

\section{Management Plan}

Patients once included in the trial were assessed pre operatively and post operatively using clinical, radiological and functional measures. All the patients were followed up at 1 month, 3 months, 6months and minimum 1 year/till implant removal whichever was earlier. The Clinical parameters that were assessed pre and post operatively include the Range of movement, limb length discrepancy, and presence or absence of pain at the nail site and by the Flynn outcome scoring ${ }^{[3]}$, All patients were evaluated and treated for life and limb threatening injuries. Displaced fractures were immobilized using skin traction with Thomas splint (femur/tibia)/Plaster Of Paris Slab/Cramer Wire Support till the day of surgery. Postoperative data collected was no. of nails, postoperative immobilization, and period of hospital stay, period of radiological union, return to normal work, any complication, and time to nail removal. Radiographs were evaluated for alignment, nail size, nail shape ( $\mathrm{C}$ or $\mathrm{S})$, callus formation, nail position, and measurement of fracture location. Major postoperative complications are defined as nonunion, delayed union, sagittal angulation of more than $20^{\circ}$, coronal angulation of more than $10^{\circ}$ (malalignment criteria based on previous studies), and infection, refracture, nail irritation requiring hardware removal, and nail breakage. Minor postoperative complications are defined as nail irritation that resolved without intervention, asymptomatic nail migration, and any perioperative problem that resolved without surgical intervention or early hardware removal.

Final outcome was graded excellent, satisfactory or poor based on criteria described by Flynn et al. 6 Functional outcome was assessed by using LEFS and DASH scoring at final follow up. Then all the data will be evaluated using statistical measures.

\section{Results}

Table 1: Age wise distribution of study population

\begin{tabular}{|c|c|c|}
\hline Age in years & No. of cases & Percentage (\%) \\
\hline 5 to 8 & 14 & $47 \%$ \\
\hline 9 to 12 & 16 & $53 \%$ \\
\hline
\end{tabular}

In the age group 5years to 8 years there were $14(47 \%)$ and 9 years to 12 years there were 16 patients $(56 \%)$.

Table 2: Sex wise distribution

\begin{tabular}{|c|c|c|}
\hline Sex & No. of cases & Percentage (\%) \\
\hline Male & 21 & $70 \%$ \\
\hline Female & 9 & $30 \%$ \\
\hline
\end{tabular}

Out of the 30 children there were 21(70\%) males and 9 (30\%) females.

Table 3: Mode of injury

\begin{tabular}{|c|c|c|}
\hline Nature of Trauma & No. of patients & Percentage (\%) \\
\hline Road traffic accident & 12 & $40 \%$ \\
\hline Fall from height & 18 & $60 \%$ \\
\hline
\end{tabular}

The major cause of fracture in our study was Road traffic accident in 12 cases $(40 \%), 18$ cases $(60 \%)$ were due to fall from a height.

Table 4: Side affected

\begin{tabular}{|c|c|c|}
\hline Side affected & No. of patients & Percentage (\%) \\
\hline Right & 18 & $60 \%$ \\
\hline Left & 12 & $40 \%$ \\
\hline
\end{tabular}

In our study right side was involved in 18 cases $(60 \%)$ and left was involved in 12 cases $(40 \%)$.

Table 5: Bone affected

\begin{tabular}{|c|c|c|}
\hline Bone affected & No of cases & Percentage (\%) \\
\hline Humerus & 1 & $3 \%$ \\
\hline Forearm & 9 & $30 \%$ \\
\hline Femur & 13 & $44 \%$ \\
\hline Tibia & 7 & $23 \%$ \\
\hline
\end{tabular}

In our study 1 case of humerus fracture (3\%), 9 cases of forearm Fractures (30\%), 13 cases of femur Fractures (44\%), 7 cases of tibia fracture $(23 \%)$. 
Table 6: Type of Fracture

\begin{tabular}{|c|c|c|}
\hline Pattern of fracture & No. of cases & Percentage \\
\hline Transverse & 15 & $50 \%$ \\
\hline Short Oblique & 7 & $24 \%$ \\
\hline Spiral & 6 & $20 \%$ \\
\hline Segmental & 1 & $3 \%$ \\
\hline Comminuted & 1 & $3 \%$ \\
\hline
\end{tabular}

In our study the fracture was transverse in 15 cases $(50 \%)$, short oblique in 7 cases $(24 \%)$, spiral in 6 cases $(20 \%)$, segmental in $1(3 \%)$ and comminuted in 1 case $(3 \%)$

Table 7: Level of fracture

\begin{tabular}{|c|c|c|}
\hline Level of fracture & No. of cases & Percentage \\
\hline Upper Third & 3 & $10 \%$ \\
\hline Middle Third & 23 & $77 \%$ \\
\hline Lower 1/3rd & 4 & $13 \%$ \\
\hline
\end{tabular}

In our study upper third of diaphysis was involved in 3 cases (10\%), middle third in 23 cases $(77 \%)$ and Lower third in 4 cases $(13 \%)$.

Table 8: Difficulties during operation

\begin{tabular}{|c|c|c|}
\hline Difficulties during operations & No. of cases & Percentage \\
\hline Difficulty in reduction & 3 & $10 \%$ \\
\hline Difficulty in passing nail & 1 & $3 \%$ \\
\hline None & 26 & $87 \%$ \\
\hline
\end{tabular}

Difficulty in reduction of fracture was encountered in 3 cases (10\%), difficulty in passing nail was noted in 1 case $(3 \%)$. This problem was because of lack of space for maneuvering the nail.

Table 9: Time for union

\begin{tabular}{|c|c|c|}
\hline Time for union & No of cases & Percentage \\
\hline Grade 2 callus at 8 weeks & 1 & $3 \%$ \\
\hline Grade 3 callus at 4 weeks & 5 & $17 \%$ \\
\hline Grade 3 callus at 6 weeks & 18 & $60 \%$ \\
\hline Grade 3 callus at 8 weeks & 6 & $20 \%$ \\
\hline
\end{tabular}

Grade 3 callus formation according to Anthony et al. scale4 was seen at 4 weeks in 5 cases(17\%), at 6 weeks in 18 cases $(60 \%)$ and 8 weeks in $6(20 \%)$ and 1 case $(3 \%)$ showed Grade 2 callus formation at 8 weeks.

Table 10: Range of motion at adjacent joints

\begin{tabular}{|c|c|c|}
\hline Range of motion of adjacent joints & No. of cases & Percentage \\
\hline Complete at 6 weeks & 24 & $80 \%$ \\
\hline $\begin{array}{c}\text { Incomplete at 6 weeks and complete at } \\
12 \text { weeks }\end{array}$ & 6 & $20 \%$ \\
\hline
\end{tabular}

Complete range of motion at hip and knee joints was obtained by the end of 6 weeks in 24cases $(80 \%)$ and in rest of 6 cases (20\%) complete range was obtained by the end of 12 weeks.

\section{Complications}

Limb length discrepancy:-Limb shortening was noted in 2 case $(7 \%)$ at the end of one year of which 1 case $(3 \%)$ had $1 \mathrm{~cm}$ shortening and 1 case had $0.5 \mathrm{~cm}$ shortening. Limb lengthening was noted in 1case (3\%) at final follow up. Malalignment: Varus angulation of 10 degree was noted in 1 case $(3 \%)$ and valgus in 1 case $(3 \%)$. Anteroposterior angulation was noted in 0 cases $(0 \%)$ our study. Rest patients had no malalignment.
Pain: Pain was noted in 1 cases $(5 \%)$ at 6 weeks, as they had skin irritation at the entry point due to protruding nail. Pain subsided after removal of nail and these patients had no complaint of pain in operated limb at the end of 1 year.

Minor complications:-Skin irritation was noted in 2 cases $(10 \%)$ and bursa formation was noted in 2 cases (10\%) in our study.

Major complications: None of the cases developed delayed union, nonunion or implant failure however 2 patients had pin entry site infection which settled after a course of antibiotics for 2 weeks.

Complications in Upper Limb: 1 case developed elbow stiffness due to lack of exercises.

\section{Discussion}

As shown in Table 1 more patents $16(56 \%)$ were in the age group of 9 to 12 years and $14(47 \%)$ were and 5 to 12 years age group. Male patients were $21(70 \%)$ and female patients were $9(30 \%)$ as shown in Table 2.

The major cause of fracture in our study (Table 3) was Road traffic accident in 12 cases (40\%), 18 cases $(60 \%)$ were due to fall from a height. Similar findings male predominance was seen in other studies like Narayanan UG, Joshua HE, Andrew MW, Mercer R, et al. ${ }^{[5]}$ Saikia KC, Bhuyan SK, Bhattacharya TD, Saikia SP et al, ${ }^{[6]}$ Khazzam M, Tassone C, Liu XC, Lyon R, [7] Iqbal M, Manzoor S, Cheema GM, Ahmed E, [8] Navdeep S, Kanav P, Suhail V, Harish D [9]. Kumar N, Chaudhary L ${ }^{[10]}$. In the present series, RTA is the most common mode of injury. There is a rise in motor vehicles on the road and improper regulation of traffic rules. Because of poor socio economic status in this region, working parents are not able to keep an eye on their children, which lead to high road traffic accidents.

As shown in Table 4, right side was involved in 18 cases $(60 \%)$ and left was involved in 12 cases $(40 \%)$. In other studies Ligier JN, Metaizeau JP, Prévot J, Lascombes P ${ }^{[11]}$, Narayanan UG, Joshua HE, Andrew MW, Mercer R, et al, ${ }^{5}$ Singh R, Sharma SC, Magu NK, Singla A. et al, ${ }^{[12]}$ Saikia KC, Bhuyan SK, Bhattacharya TD, Saikia SP et al, ${ }^{[6]}$ showing the same outcome of right- sided involvement. We did not encounter with any case of bilateral involvement.

As shown in Table 6,type of fracture was transverse in 15 cases $(50 \%)$, short oblique in 7 cases $(24 \%)$, spiral in 6 cases $(20 \%)$, segmental in $1(3 \%)$ and comminuted in 1 case $(3 \%)$. Our study is comparable to other studies Flynn JM, Hresko T, Reynolds RA, Blasier RD et al. ${ }^{[3]}$ reported most frequent fracture type was transverse in middle 3rd of shaft. Sink EL, Faro F, Polousky J, Flynn K, Gralla J ${ }^{[13]}$. showed improved results of pediatric femoral fractures with the use of TENS in stable fractures. We concluded that transverse fracture is maximum in number \& best stabilized with TENS.

In our study Table 7 site of fracture, upper third of diaphysis was involved in 3 cases (10\%), middle third in 23 cases $(77 \%)$ and Lower third in 4 cases (13\%). In other studies also like Houshian S, Bajaj SK et al, ${ }^{[14]}$ Singh R, Sharma SC, Magu NK, Singla A. et al, ${ }^{[12]}$ Khazzam M, Tassone C, Liu XC, Lyon $\mathrm{R},{ }^{[7]}$ maximum number of fractures occurred in middle $1 / 3$ rd of shaft.

Most common complication seen in our study was entry site irritation and pain. This was seen due to prominence of nail end (more than $1 \mathrm{~cm}$ outside the medullary cavity). To reduce this complication: We realize that bending of nail ends to be avoided, less than $1 \mathrm{~cm}$ nail should be left outside the 
medullary cavity and passive knee bending just after approximation of skin to sink the nail in muscles.

Two cases developed skin erosion at entry site by prominent nail end and was subsided after nail removal. We encountered with one case $(3.33 \%)$ of infected Grade-II compound fracture of femur that approached us after 3 days of injury. Fracture was stabilized by TEN after wound debridement and appropriate antibiotics were given after culture sensitivity but infection did not subside, so early implant removal was done in 4 months. We did not encounter any delayed union, nonunion, malunion or nail migration. Limb length was measured clinically in each follow up and we found no significant limb length discrepancies or gait abnormality.

\section{References}

1. Gardner MJ, Lawrence BD, Griffith MH. Surgical treatment of pediatric femoral shaft fractures. Current opinion in pediatrics. 2004; 16(1):51-7.

2. Flynn JM, Hresko T, Reynolds RA, Blasier RD, Davidson R, Kasser J. Titanium elastic nails for pediatric femur fractures: a multicenter study of early results with analysis of complications. Journal of Pediatric Orthopaedics. 2001; 21(1):4-8.

3. Flynn JM, Hresko T, Reynolds RA, Blasier RD, Davidson R, Kasser J. Titanium elastic nails for pediatric femur fractures: a multicenter study of early results with analysis of complications. Journal of Pediatric Orthopaedics. 2001; 21(1):4-8.

4. Stans AA, Morrissy RT, Renwick SE. Femoral shaft fracture treatment in patient's age 6 to 16 years. Journal of Pediatric Orthopaedics. 1999; 19(2):222-8.

5. Narayanan UG, Joshua HE, Andrew MW, Mercer R, Benjamin AA. Complications of elastic stable intramedullary nail fixation of paediatric femoral fractures, and How to avoid them. J Pediatr Orthop. 2004; 24(4):363-9.

6. Saikia KC, Bhuyan SK, Bhattacharya TD, Saikia SP. Titanium elastic nailing in femoral diaphyseal fractures of children in 6-16 years of age. Indian journal of orthopaedics. 2007; 41(4):381.

7. Khazzam M, Tassone C, Liu XC, Lyon R, Freeto B, Schwab $\mathrm{J}$ et al. Use of flexible intramedullary nail fixation in treating femur fractures in children. Am J Orthop. 2009; 38(3):E49-55.

8. Iqbal M, Manzoor S, Cheema GM, Ahmed E. Comparative Study of Fracture Shaft of Femur in Children Treated with Titanium Elastic Nail and Early External Fixator. Annals of King Edward Medical University. 2010; 16(2):82-.86.

9. Navdeep S, Kanav P, Suhail V, Harish D. Closed reduction and internal fixation of fractures of the shaft of the femur by the Titanium Elastic Nailing System in children. The Internet Journal of Orthopedic Surgery, 2010, 17(1).

10. Kumar N, Chaudhary L. Titanium Elastic Nails for Pediatric Femur Fractures: Clinical and Radiological Study. Surgical Science. 2010; 1(01):15.

11. Ligier JN, Metaizeau JP, Prévot J, Lascombes P. Elastic stable intramedullary nailing of femoral shaft fractures in children. The Journal of bone and joint surgery. British. 1988; 70(1):74-7.

12. Singh R, Sharma SC, Magu NK, Singla A. Titanium elastic nailing in pediatric femoral diaphyseal fractures. Indian Journal of Orthopaedics. 2006; 40(1):29.

13. Sink EL, Faro F, Polousky J, Flynn K, Gralla J.
Decreased complications of pediatric femur fractures with a change in management. Journal of Pediatric Orthopaedics. 2010; 30(7):633-7.

14. Houshian S, Bajaj SK. Forearm fractures in children. Single bone fixation with elastic stable intramedullary nailing in 20 cases. Injury. 2005; 36(12):1421-6. 